\title{
Mathematics Anxiety: Mapping the Literature by Bibliometric Analysis
}

\author{
Zara Ersozlu ${ }^{*}$, Mehmet Karakus ${ }^{2}$ \\ ${ }^{1}$ Faculty of Arts and Education, Deakin University, AUSTRALIA \\ 2 RPS International, New Territories, HONG KONG
}

Received 3 December 2018 - Revised 27 December 2018 • Accepted 30 December 2018

\begin{abstract}
The goal of this study is to analyse the publications on mathematics anxiety to contribute to the development of the related literature. A total of 537 papers on mathematics anxiety published in various databases of Web of Science between 2000 and 2018 years were retrieved and analysed through bibliometric analysis approach. Bibliographic coupling of the source, the authors, the countries, the institutions, the publications and co-occurrences of the author keywords were analysed and visualised through VOS Viewer software. Maths anxiety has been studied frequently with the concepts of anxiety, motivation, self-efficacy, self-concept, maths performance, maths achievement, gender-related differences, test anxiety, working memory, arithmetic, mental arithmetic, and numeracy. Frontiers in Psychology and Learning and Individual Differences have been the top journals, and the University of Chicago has been the most influential institution, and the USA has had a significant prevalence in this area.
\end{abstract}

Keywords: bibliometric analysis, bibliometric visualization, mathematics, mathematics anxiety

\section{INTRODUCTION}

Mathematics anxiety can be defined as feelings of fear, tension, and apprehension that some people feel when dealing with mathematical issues (Ashcraft, 2002). Maths anxiety has serious psychological and psychosomatic symptoms that might sometimes be difficult to overcome for most of the individuals (Pletzer, Kronbichler, Nuerk, \& Kerschbaum, 2015). There are many research studies demonstrating the negative effect of maths anxiety on maths performance and maths achievement $(\mathrm{Ma}, 1999)$. Most of the scholars in this area argue that the adverse impact of maths anxiety on maths performance is mediated by a transient reduction in the cognitive resources (i.e., working memory) that everyone needs to complete the cognitive tasks in maths (Ramirez, Shaw, \& Maloney, 2018). Pletzer et al. (2015) found evidence that high mathematics anxiety levels reduce the neural efficiency of the individuals and thus they are not able to effectively use the cognitive resources that they need to operate for maths success. Sarkar, Dowker, and Kadosh (2014) proved that the students who can overcome their affective concerns stemming from maths-anxiety could improve their working memory efficiency and maths performance.

Many researchers included investigation of the causes of mathematics anxiety in their research. Wang et al. (2014) presented evidence that maths anxiety can be taken up as a part of the trait anxiety and some genetic factors play an important role along with various environmental factors in the development of maths anxiety. Ma and Xu (2004) and Gunderson, Park Maloney, Beilock, and Levine (2018) found evidence that poor maths skills and lower levels of maths achievement have adverse effects on students' self-efficacy levels and cause them to develop maths anxiety. Maloney, Ramirez, Gunderson, Levine, and Beilock (2015) found that parents with high levels of maths anxiety trigger their children to develop maths anxiety. High-maths-anxious teachers can also trigger their students to develop maths anxiety as it was proven by Markovits (2011) and Ramirez, Hooper, Kersting, Ferguson, and Yeager (2018).

If the parents provide firm support and hold high parental expectations, they can reduce their children's maths anxiety and increase their math achievement (Vukovic, Roberts, \& Green Wright, 2013). If teachers and parents

(C) 2019 by the authors; licensee Modestum Ltd., UK. This article is an open access article distributed under the terms and conditions of the Creative Commons Attribution License (http://creativecommons.org/licenses/by/4.0/). \zehra.ersozlu@deakin.edu.au (*Correspondence) \ karakusmehmet44@gmail.com 


\section{Contribution of this paper to the literature}

- The purpose of this study is to analyse the characteristics of the publications on mathematics anxiety in order to contribute to the development of the literature in this area.

- The hottest topics in the most recent literature have been mathematical anxiety, arithmetic, numeracy, and math performance.

- The number of publications increased significantly starting from 2012 year and reached the highest level in 2017 year.

boost the maths motivation levels of anxious students and give them appropriate appraisal cues, they can overcome the cognitive and affective antecedents of anxiety and increase their maths performance (Wang et al., 2015).

The goal of this study is analysing the characteristics of the publications on maths anxiety to contribute to the development of the literature in this area. Bibliometric analysis was used to analyse the aspects of these publications. The term bibliometrics means the application of quantitative methods to any kinds of resources in an area of research (Pritchard, 1969). Using this approach, it is possible to comprehend various features of the publications in a field by categorising them according to their sources, countries of origin, authors, citations, affiliated institutions, keywords, and topics. Employing more advanced analysis techniques, we can create a map based on bibliographic data, such as mapping of co-authorship, co-occurrences of keywords, co-citations, and bibliographic coupling of sources, authors, citations, institutions, and countries.

Extracting the numbers and the citations of publications, which is among the most important indicators of academic performance, enables comparison between specific institutions, countries, authors, and journals. Bibliometrics employ specific patterns of selected publications to analyse these patterns quantitatively. It is possible to use both descriptive and evaluative methods to analyse publications in this approach. Descriptive methods are simpler than evaluative methods and are used only to describe the characteristics of publications e.g. the numbers and citations of publications according to the authors, institutions, sources, countries. Evaluative methods make possible more complex comparisons and determine the impact of publications while the descriptive methods allow only unilateral and straightforward comparisons (McBurney \& Novak, 2002). Using evaluative methods, it is possible to extract co-citation maps, co-authorship maps, co-occurrences of keywords, citation maps, or bibliographic coupling of documents, sources, authors, organisations, and countries.

In this study, Web of Science (WoS), which is the leader of the scientific information in the world, was used as the primary source of information. The scientific data in WoS enables the researchers to use both descriptive and evaluative analysis methods. Social Sciences Citation Index (SSCI), Science Citation Index (SCI) Expanded, Arts and Humanities Citation Index (AHCI), and Emerging Sources Citation Index (ESCI) were among the most important databases in WoS Core Collection containing thousands of prestigious journals from all around the world. These databases were used in this study to download and analyse the related information.

\section{METHODOLOGY AND MATERIAL}

To retrieve all the publications on mathematics anxiety, WoS was searched on 23rd of November 2018 for the research items published between 2000 and 2018 years. The keywords of math anxiety mathematical anxiety, and mathematics anxiety were entered into the topic field and these keywords were searched in the author keywords, keywords plus, titles, and abstracts of the publications. Social Sciences Citation Index (SSCI), Science Citation Index (SCI) Expanded, Arts and Humanities Citation Index (AHCI), and Emerging Sources Citation Index (ESCI) were selected as the Citation Indexes in Web of Science Core Collection. Among the document types, meeting abstracts, proceedings papers, corrections, new items, and letters were excluded from the study, because some of those items prevented us from seeing the impact of top journals. After excluding the publications that are unrelated to the topic of math anxiety, a total of 537 documents were extracted. 512 of them were articles, 18 of them were reviews, 7 of them were editorial materials, and 2 of them were book chapters.

The selected papers belonged to these categories of WoS; Education and Educational Research (178 items), Educational Psychology (91 items), Multidisciplinary Psychology (78 items), Experimental Psychology (43 items), Developmental Psychology (29 items), Neurosciences (28 items), Multidisciplinary Sciences (20 items), Psychology (19 items), Education Scientific Disciplines (18 items), Social Psychology (17 items), Clinical Psychology (15 items), Behavioral Sciences (13 items), Communication (11 items), Psychiatry (9 items), Special Education (8 items), Applied Psychology" (7 items), Biological Psychology (7 items), and there are some of other categories with smaller numbers.

The bibliometric analysis approach was used in this study along with bibliometric visualisation methods. The research trend and characteristics of publications in a specific area can be explored quantitatively through bibliometric analysis method (McBurney \& Novak, 2002). There are several bibliometric visualisation tools to 
Table 1. Records of Publications and Percentages

\begin{tabular}{|c|c|c|}
\hline Publication Years & Publication Records & $\%$ of 537 \\
\hline 2018 & 52 & 9.68 \\
\hline 2017 & 85 & 15.82 \\
\hline 2016 & 61 & 11.35 \\
\hline 2015 & 63 & 11.73 \\
\hline 2014 & 50 & 9.31 \\
\hline 2013 & 44 & 8.19 \\
\hline 2012 & 33 & 6.14 \\
\hline 2011 & 21 & 3.91 \\
\hline 2010 & 21 & 3.91 \\
\hline 2009 & 19 & 3.53 \\
\hline 2008 & 15 & 2.79 \\
\hline 2007 & 12 & 2.23 \\
\hline 2006 & 14 & 2.60 \\
\hline 2005 & 8 & 1.48 \\
\hline 2004 & 6 & 1.11 \\
\hline 2003 & 13 & 2.42 \\
\hline 2002 & 7 & 1.30 \\
\hline 2001 & 8 & 1.48 \\
\hline 2000 & 5 & 0.93 \\
\hline
\end{tabular}

manifest a structural outline of an area of research (Garfield, 2009). VOSviewer is among the most popular computer software including various visualising techniques (Eck \& Waltman, 2010, 2014a, 2014b; Eck, Waltman, \& Glanzel, 2017). In this paper, VOS Viewer software was employed to collect, analyse, and visualise the bibliographic data. The bibliographic coupling of the sources, the authors, the countries, the institutions, the publications and cooccurrences of the author keywords were analysed and visualised.

Publication records and the percentages of the publications by publication years are presented in Table 1. The results show that the number of publications differs from year to year and there is a meaningful increase in the number of publications starting from 2012 to the year 2017 has the highest number and 2005 has the lowest number of publications. The publications before 2000 were excluded from this study to focus on the recent trends of this area. There were a small number of publications before 2000, and they were divided into years unsteadily; however, some of them had high citation records. If they were not excluded, they would have prevented the impact of the latest publications being revealed.

\section{RESULTS}

In this part of the paper, descriptive and evaluative analysis results are presented. Bibliographic coupling of the sources, co-occurrences of the author keywords, the bibliographic coupling of the authors, bibliographic coupling of the countries, bibliographic coupling of the institutions, and bibliographic coupling of the publications were extracted through VOS Viewer software.

\section{Bibliographic Coupling of the Sources}

The bibliographic coupling of the sources has been shown with density visualisation in Figure 1 . Only the sources that have at least five publications have been included in this study. Of the 284 sources, 13 met the threshold. For all the journals, bibliographic coupling links total strengths were calculated. First two were Frontiers in Psychology and Learning and Individual Differences. Both of them have the same number of documents (31), the second one has more citations (577) than the first one (184) and the first one has more total link strength (8676) than the second one (7560). For each journal, the first numbers are the numbers of publications, the second ones are the numbers of citations, and the third ones are their total link strengths: Frontiers in Psychology (31; 184; 8676), Learning and Individual Differences $(31 ; 577 ; 7560)$, Plos One (12;140;3059), Journal of Educational Psychology (6; 253; 2282), British Journal of Educational Psychology (6; 36; 2151), Journal of Psychoeducational Assessment (7; 194; 1995), International Journal of Science and Mathematics Education (6; 41; 1518), European Journal of Psychology of Education (5; 190; 1337), Educational Psychology $(6 ; 56 ; 1097)$, Psychological Reports $(14 ; 96 ; 1000)$, School Science and Mathematics $(6 ; 129 ; 888)$, Sex Roles (5; 133; 755), and International Journal of Mathematical Education in Science and Technology (5; 25; 690). The scope of most of those journals in psychology and only three of those journals are focusing on science and maths education. 


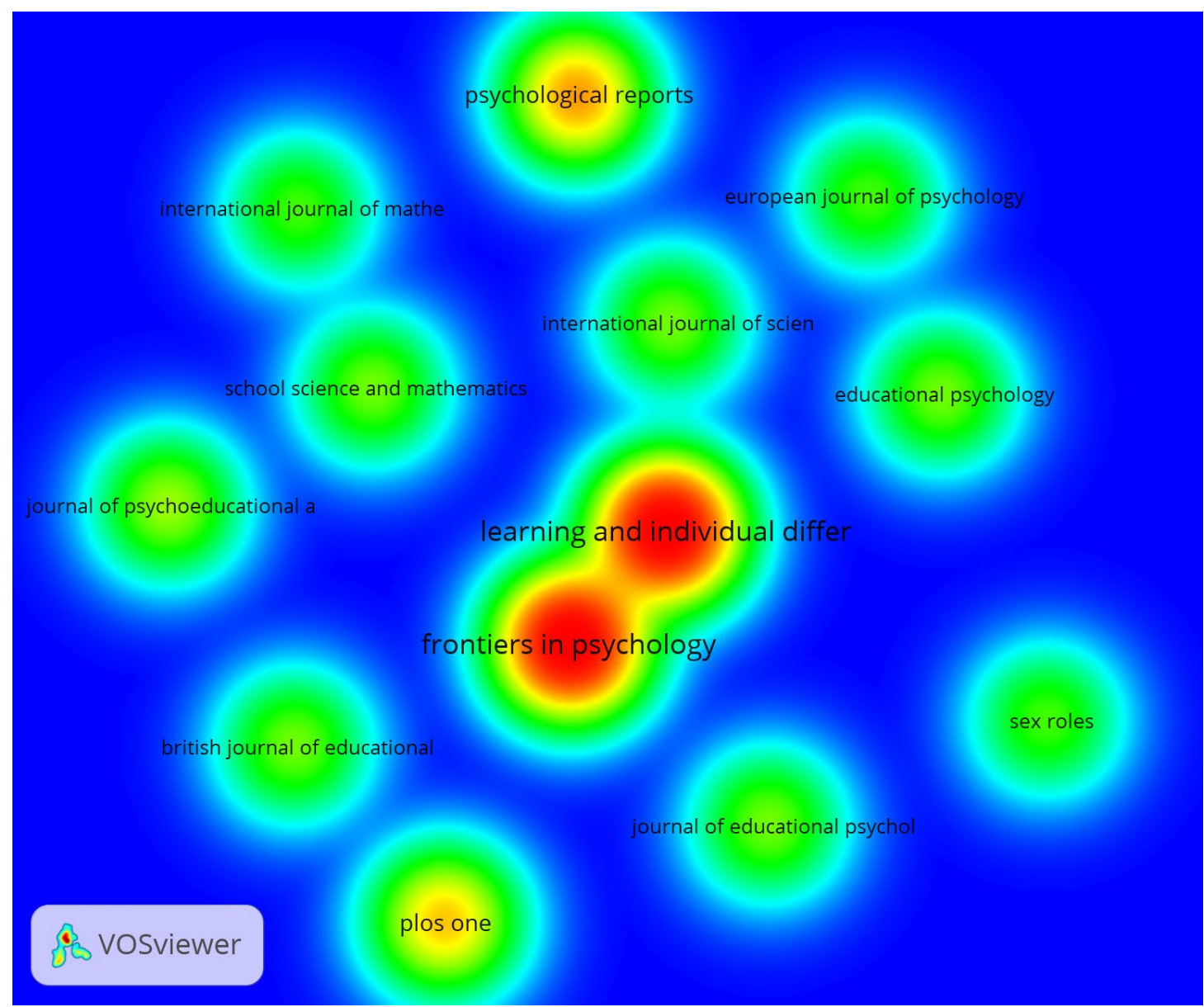

Figure 1. Bibliographic coupling of the sources (density visualization)

\section{Co-Occurrences of the Author Keywords}

Co-occurrences of the author keywords have been shown in Figure 2. Only the keywords that occurred at least ten times were included in the analysis. Of the 1062 terms, 20 keywords met the threshold. For all the keywords, the co-occurrence links' total strengths were calculated related to the other keywords. Math anxiety was the strongest keyword with 117 occurrences and 77 total link strength. Math anxiety is the most preferred phrase to express this concept. Not only in the author keywords, but it is also much more frequently used in the titles and abstracts of the related publications than the concepts of mathematics anxiety and mathematical anxiety. 


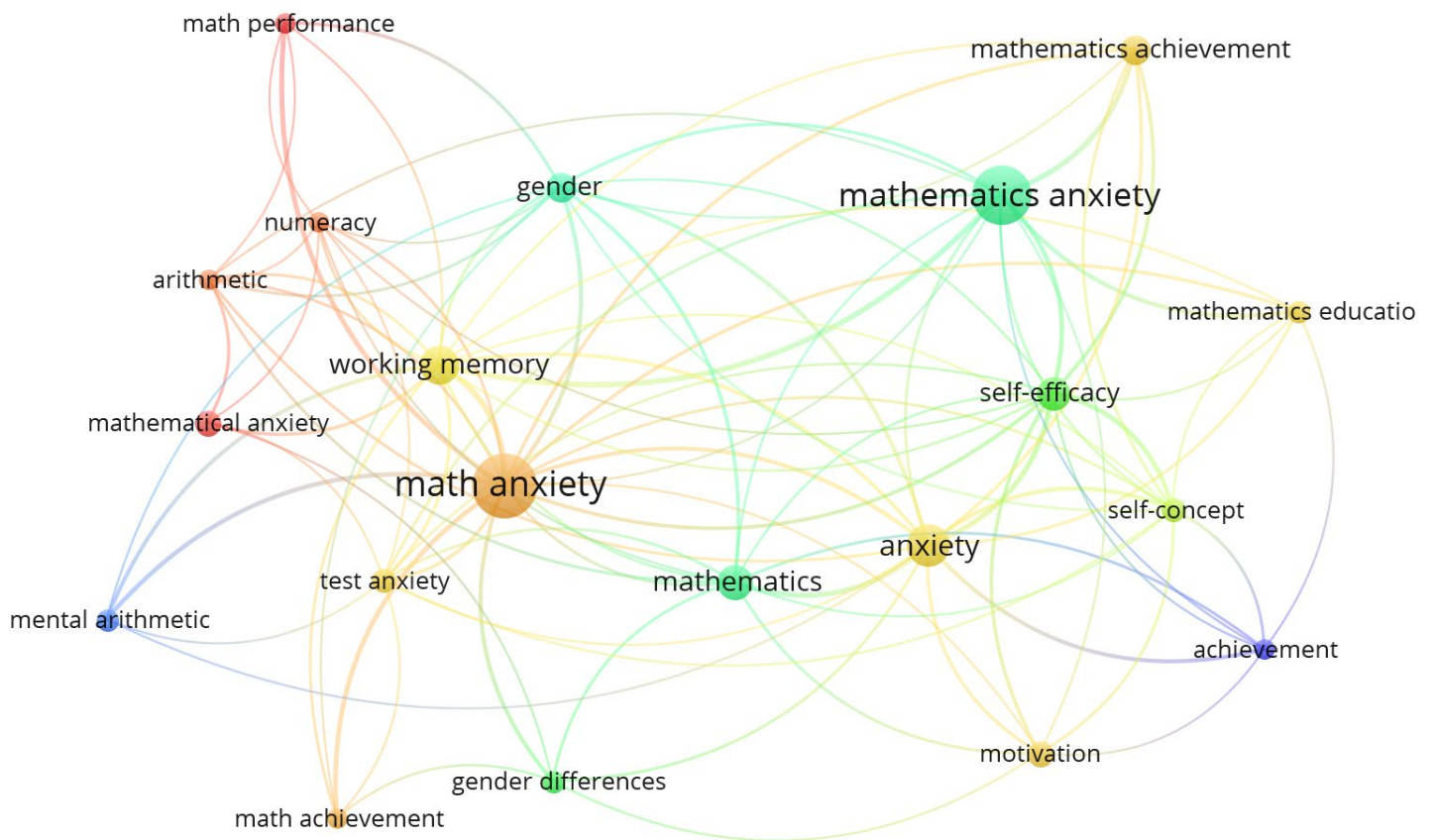

\section{VOSviewer}

\begin{tabular}{llll}
\hline 1 & 1 & \\
2012 & 2013 & 2014 & 2015
\end{tabular}

Figure 2. Co-occurences of the author keywords (overlay visualization)

The analysis yielded four clusters for the keywords. Each cluster shows the most co-occurred keywords that are connected. For all the keywords, the first numbers are the numbers of occurrences and the second ones are the total link strengths. There are 6 items in the first cluster: These are: anxiety $(46 ; 61)$, achievement $(11 ; 13)$, mathematics $(32 ; 32)$, motivation $(16 ; 15)$, self-efficacy $(28 ; 43)$, and self-concept $(14 ; 28)$. There are 6 items in the second cluster: working memory $(41 ; 57)$, arithmetic $(10 ; 16)$, mathematical anxiety $(16 ; 9)$, mental arithmetic $(13 ; 15)$, numeracy $(10 ; 11)$, and test anxiety $(15 ; 17)$. There are five items in the third cluster: math anxiety $(117 ; 77)$, gender $(22 ; 32)$, gender differences $(13 ; 12)$, math achievement $(11 ; 13)$, and math performance $(10 ; 15)$. There are three items in the fourth cluster: mathematics anxiety $(96 ; 49)$, mathematics achievement $(22 ; 24)$, and mathematics education $(13 ; 15)$. In Figure 2, the different colours show the publication dates of the related works in which these keywords cooccurred. This figure shows that the hottest topics in the literature are mathematical anxiety, arithmetic, numeracy, and math performance.

\section{Bibliographic Coupling of the Authors}

Bibliographic coupling of the authors has been illustrated in Figure 3. Each author had at least eight publications to be included in the analysis. Of the 1133 authors, 12 met the thresholds. For each author, bibliographic coupling links' total strength was extracted concerning the other authors. The first author was S.L. Beilock. (from the University of Chicago, the USA) with 23 publications, 943 citations, and 10135 total link strength. For all the authors, the first numbers are the numbers of publications, the second ones are the numbers of citations, and the third ones are their total link strengths. The other authors are: .E.A. Maloney (from University of Chicago, the USA) (15; 398; 7712), G. Ramirez (from University of Chicago, the USA) (13; 532; 6916), S.C. Levine (from University of Chicago, the USA) (13; 564; 6266), M.I. Nunez-Pena (from University of Barcelona, Spain) (12; 135; 5688), M. Suarez-Pellicioni (from University of Barcelona, Spain) $(12 ; 135 ; 5688)$, D. Szucs (University of Cambridge, England) $(9 ; 156 ; 4898)$, A. Devine (University of Cambridge, England) $(8 ; 156 ; 4774)$, I.C. Mammarella (University of Padua, Italy) $(8 ; 55 ; 4398)$, E.A. Gunderson (Temple University, the USA) $(9 ; 468 ; 4241)$, H.C. Nuerk (University of Tubingen, Germany) $(8 ; 51$; 3097), M. Baloglu (Hacettepe University, Turkey) $(8 ; 105 ; 1333)$. The most important four authors in this area are 


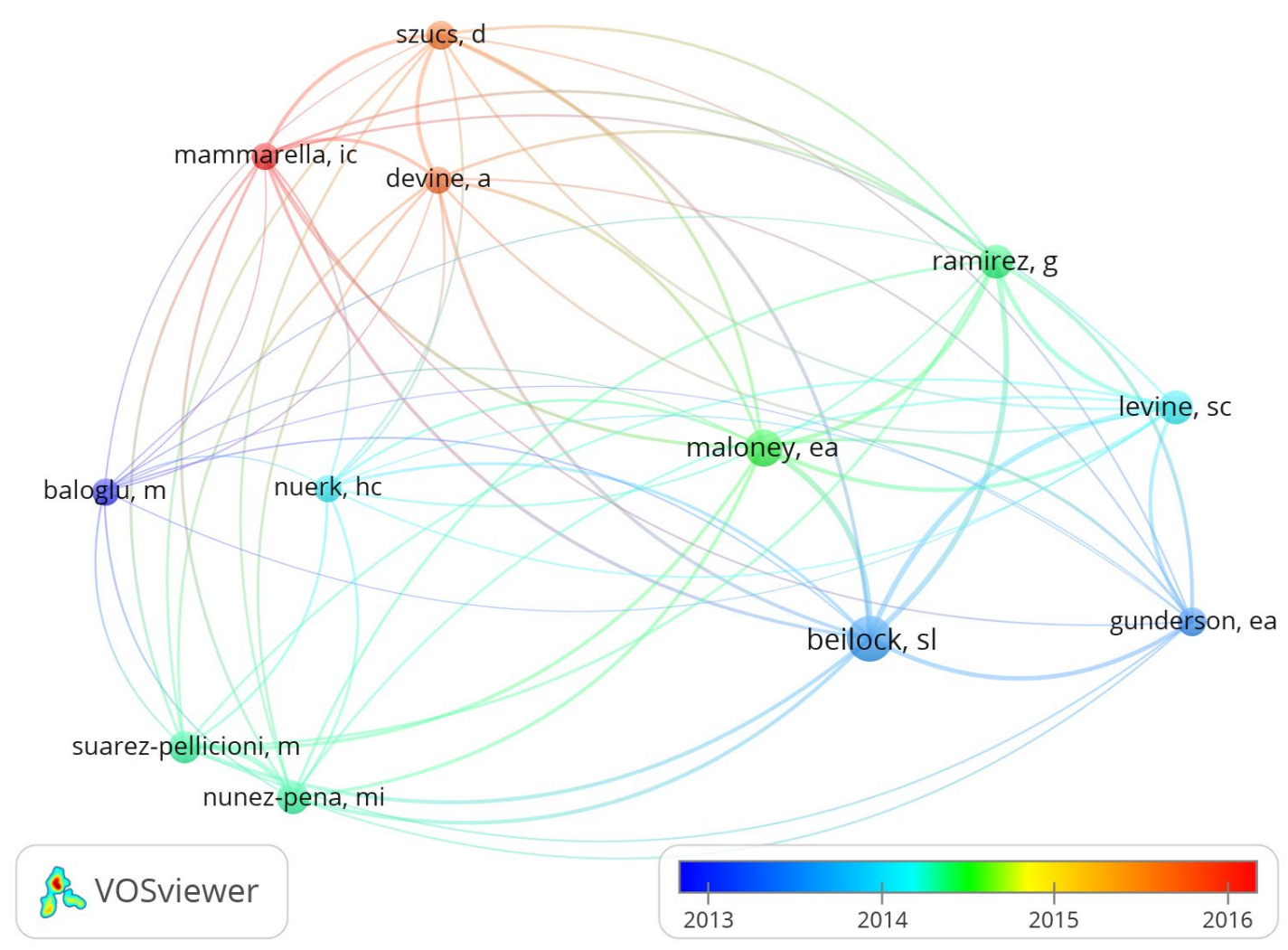

Figure 3. Bibliographic coupling of the authors (overlay visualization)

from the University of Chicago, and there are two authors from each of these universities consecutively: the University of Barcelona and the University of Cambridge.

Colours in Figure 3 show the publication years of the items written by these authors. The results show that I.C. Mammarella, A. Devine, and D. Szucs authored the most recent publications in this area of research. These three authors from Italy and England formed a research team and co-authored many publications recently in the area of maths anxiety.

\section{Bibliographic Coupling of the Countries}

Bibliographic coupling of the countries has been illustrated in Figure 4 with overlay visualisation. Only the countries that have at least ten publications have been included in this analysis. Of the 52 countries, 13 met the threshold. For each country, bibliographic coupling links' total strength was calculated concerning the other countries. With a significant difference, the top country in this list was the USA with 220 publications, 4774 citations, and 94394 total link strength. For the other countries, the first numbers are the numbers of publications, the second ones are the numbers of citations, and the third ones are their total link strengths. The other countries were; England $(56 ; 614 ; 47828)$, Germany $(39 ; 637 ; 28108)$, Spain $(38 ; 199 ; 26630)$, Canada $(29 ; 585 ; 23450)$, Turkey $(45 ; 210 ; 20190)$, Italy $(18 ; 122 ; 20111)$, Australia $(28 ; 553 ; 17602)$, Israel $(13 ; 101 ; 13741)$, Austria $(14 ; 151 ; 12104)$, Netherlands $(10 ; 170$; 9228), People's Republic of China (10; 215; 7458), and Singapore (10; 175; 4932). Colours in Figure 4 show the years of publications regarding the countries of origin. The results show that England, Italy, Netherlands, Spain, and Israel have the most recent publications in this area. 


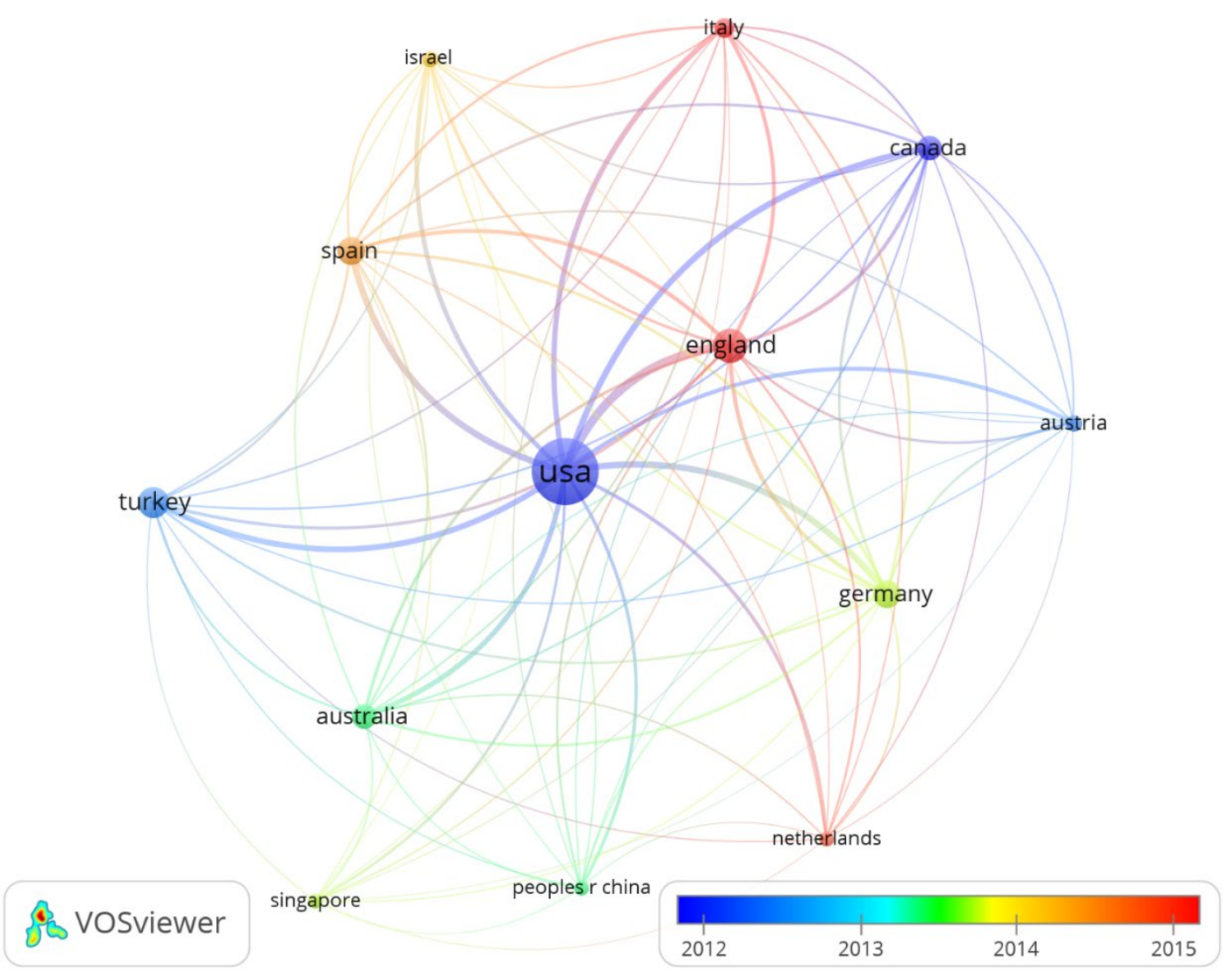

Figure 4. Bibliographic coupling of the countries (overlay visualization)

\section{Bibliographic Coupling of the Institutions}

Bibliographic coupling of the institutions has been illustrated in Figure 5 with overlay visualisation. Only the organisations that have at least seven publications been included in the analysis. Of the 510 organisations, 14 met the threshold. For all the organisations, bibliographic coupling links' total strengths were calculated in respect of the other organisations. University of Chicago (USA) has been the top organisation with 29 publications, 1004 citations, and 8839 total link strength. University of Cambridge (England) was the second with 14 publications, 196 citations, and 7137 total link strength. The other universities are as follows (consecutively, the first number shows the number of publications, the second one shows the number of citations, and the third one shows the total link strength): University of Barcelona (Spain) (13; 135; 4670), University of Padua (Italy) (8; 55; 4582), University of Oxford (England) $(9 ; 236 ; 3937)$, University of Haifa (Israel) $(7 ; 57 ; 3717)$, University of California, Los Angeles (USA) $(7 ; 106 ; 3574)$, University of Tubingen (Germany) $(8 ; 39 ; 3244)$, Stanford University (USA) $(8 ; 141 ; 3094)$, Queen's University Belfast (Northern Ireland) $(9 ; 53 ; 3089)$, University of Western Ontario (Canada) $(9 ; 311 ; 2663)$, University of Munich (Germany) (8; 438; 1617), University of Konstanz (Germany) (7; 256; 1395), and Gaziosmanpasa University (Turkey) $(7 ; 84 ; 1346)$. 


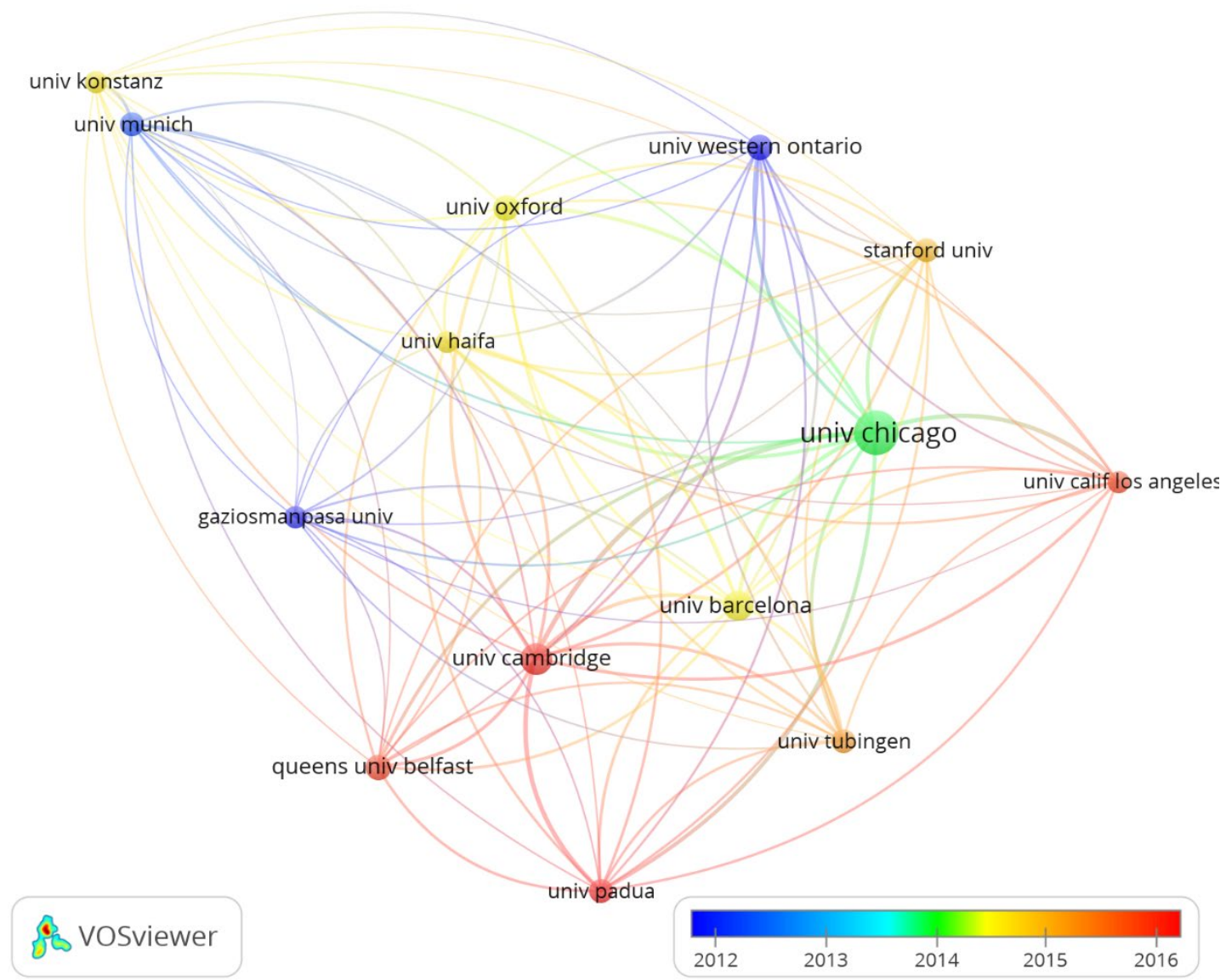

Figure 5. Bibliographic coupling of the institutions (overlay visualization)

In this list, there are three universities from the USA, three universities from Germany, two universities from England, and a university from each of those countries: Spain, Italy, Turkey, Canada, and Northern Ireland. Different colours in Figure 5 stand for the publication years of the items originated from those institutions. The results show that the most recent publications in math anxiety originated from these four universities: University of Cambridge (England), University of Padua (Italy), University of California, Los Angeles (USA), and Queen's University Belfast (Northern Ireland).

\section{Bibliographic Coupling of the Publications}

Bibliographic coupling of the publications has been illustrated with network visualisation in Figure 6. Only the publications that have at least 100 citations been included in the analysis. Of the 537 documents, 12 met the threshold. For each publication, bibliographic coupling links' total strength was calculated concerning the other publications. Ashcraft and Kirk (2001) was the strongest publication with 404 citations and 26 total link strength. The second and the fourth ones were first authored by Ashcraft: Ashcraft (2002) and Ashcraft and Krause (2007). For all the publications, the first number represents the publication year, the second one is the number of citations, and the last one is the total link strength. The other publications are listed consecutively; Ashcraft $[2002 ;(247 ; 28)]$, Beilock, Gunderson, Ramirez, and Levine [2010; (192; 19)], Ashcraft and Krause [2007; (148; 20)], Frenzel, Pekrun, and Goetz [2007; (137; 27)], Goetz, Frenzel, Pekrun, Hall, and Lüdtke [2007; (130; 28)], Gunderson, Ramirez, Levine, and Beilock [2012; (115; 21)], Martin and Marsh [2008; (112; 18)], Ma and Xu [2004; (107; 24)], Ferla, Valcke, and Cai [2009; $(103 ; 20)]$, Imbo and Vandierendonck [2007; $(101 ; 17)]$, and Lee [2009; $(100 ; 34)]$. 


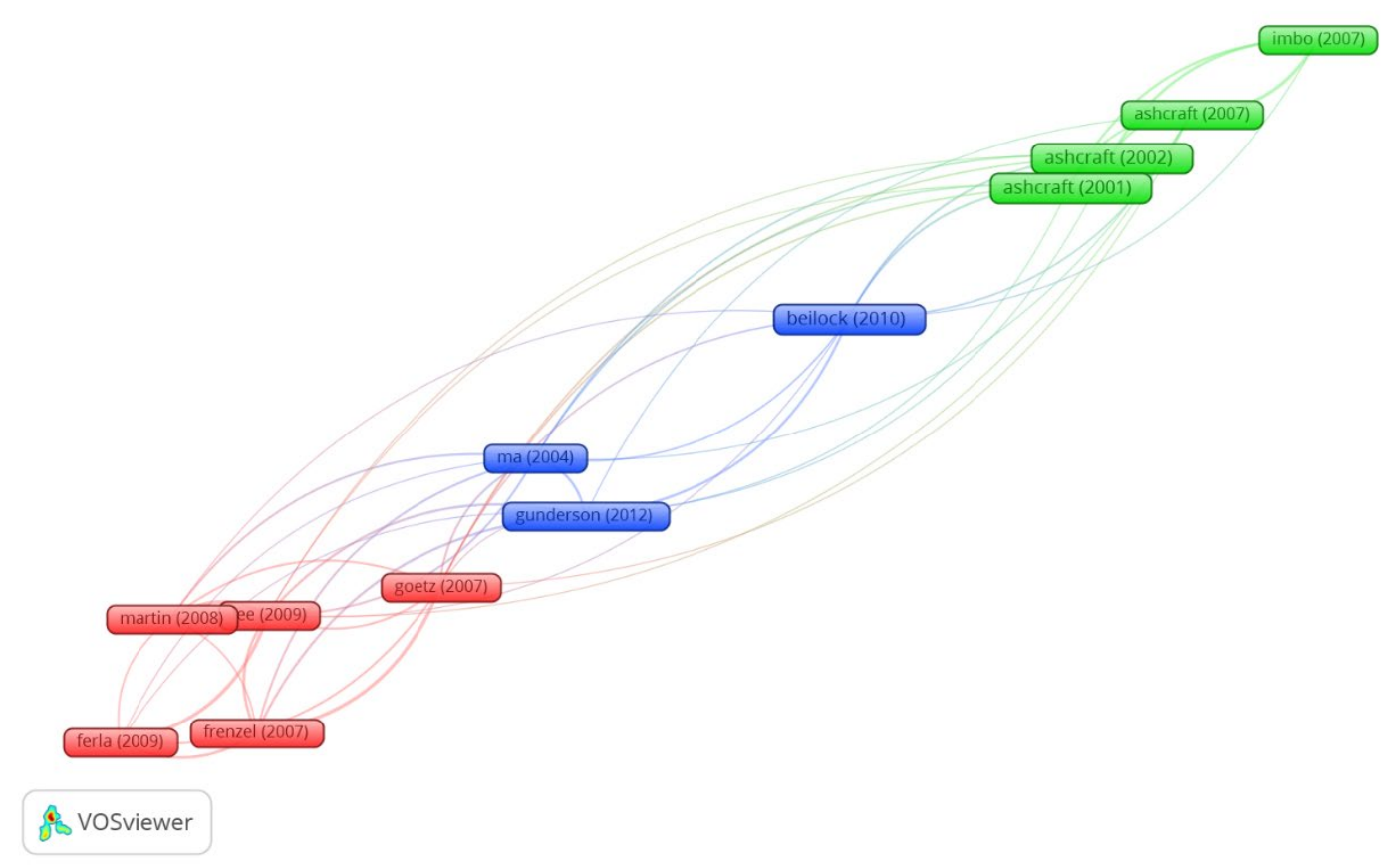

Figure 6. Bibliographic coupling of the publications (network visualization)

Notes: Ashcraft (2001): Ashcraft \& Kirk (2001); Beilock (2010): Beilock, Gunderson, Ramirez, \& Levine (2010); Ashcraft (2007): Ashcraft \& Krause (2007); Frenzel (2007): Frenzel, Pekrun, \& Goetz (2007);Goetz (2007): Goetz, Frenzel, Pekrun, Hall, \& Lüdtke (2007); Gunderson (2012): Gunderson, Ramirez, Levine, \& Beilock (2012); Martin (2008): Martin \& Marsh (2008); Ma (2004): Ma \& Xu (2004); Ferla (2009): Ferla, Valcke, \& Cai (2009); Imbo (2007): Imbo \& Vandierendonck (2007).

The software categorised the publications within three clusters in which the publications are linked with each other at the highest level for the items in other clusters. These clusters are shown in Figure 6 in different colours. Although there are a few exceptions, the publications in each cluster shows the publications co-authored by the same scholars. Ferla et al. (2009), Frenzel et al. (2007), Goetz et al. (2007), Lee (2009), and Martin and Marsh (2008) are in the first cluster. Ashcraft and Kirk (2001), Ashcraft (2002), Ashcraft and Krause (2007), and Imbo and Vandierendonck (2007) are in the second cluster. Beilock et al. (2010), Gunderson et al. (2012), and Ma \& Xu (2004) are in the third cluster.

The top article in this field is Ashcraft, M. H., and Kirk, E. P. (2001). In this research paper, the authors reported the results of three different experiments that examined the cognitive consequences and correlates of mathematics anxiety. The results showed that persons who suffered from a high level of maths anxiety had smaller working memory spans, especially at the computation-based span tasks. When working memory capacity reduced, reaction time and errors increased during the experiments. The same reduction occurred at the working memory-intensive transformation tasks. Besides, maths anxiety had a negative effect on online performance in maths-related tasks because of a transitory disruption of working memory. The authors explained the underlying mechanisms that caused a disruption of central executive processes and developed recommendations about maths anxiety, working memory capacity, and functioning.

The second most influential publication in this field is Ashcraft, M. H. (2002). This review paper attempts to define the concept of maths anxiety and to clarify the relationships between maths anxiety, maths competence, and cognitive consequences of this problem. He stated that highly maths-anxious students are inclined to avoid maths in a way that reduces their levels of maths competence and maths achievement. Maths anxiety has a negative effect on cognitive processing through its destructive effects on working memory. There are pieces of evidence that the teaching styles of the educators are among the important factors that increase maths anxiety, yet there is an ambiguity in the literature on the specific causes of maths anxiety. The author stated that there is a gap in the literature on the origins of maths anxiety and its effects on brain activity need to be explored in detail including both its cognitive and emotional dimensions.

The third most influential publication in this field is Beilock et al. (2010). This research article showed that individuals' fear and anxiety about doing math have a negative effect on their maths achievement. More specifically, this article proved that female elementary school teachers' maths anxiety carries negative outcomes to 
their female students by decreasing their maths achievement. They proved that female teachers' anxieties have a negative effect on female students' beliefs on their capability of maths and their negative beliefs decrease their maths achievement. This was a widespread problem in the USA since most of the early elementary school teachers were female in this country. The first and second-grade female teachers were asked to complete maths anxiety scales. The researchers also assessed the maths achievement of their students. While there was not any relationship between these teachers' maths anxiety and their students' maths achievement at the beginning of the academic year, the girls' maths achievement levels decreased by the end of the year because of their endorsement of the stereotype that "girls are worsethan boys in math".

\section{DISCUSSION}

In this study, a bibliometric analysis approach was used to retrieve and analyse the publications on mathematics anxiety. SSCI, SCI-Expanded, AHCI, and ESCI databases of WoS were searched for this purpose. The bibliographic data was analysed using evaluative techniques and visualised through VOS Viewer. Bibliographic coupling of the sources, co-occurrences of the author keywords, the bibliographic coupling of the authors, bibliographic coupling of the countries, bibliographic coupling of the institutions, and bibliographic coupling of the publications were analysed and visualised.

Bibliographic coupling of the co-occurrences of author keywords showed that the most frequently used term for this concept is math anxiety. Math anxiety has frequently been studied with general anxiety, student motivation, self-efficacy of students, self-concept of students, gender-related differences, their maths performance and maths achievement levels. In another group of researches, maths anxiety and test anxiety are frequently studied with working memory, arithmetic, mental arithmetic, and numeracy. The most recent researches in this literature are about mathematical anxiety, arithmetic, numeracy, and maths performance.

Bibliographic coupling of the sources showed that the top journals in mathematics anxiety literature are Frontiers in Psychology and Learning and Individual Differences. The other important journals in this area are Plos One, Journal of Educational Psychology, British Journal of Educational Psychology, Journal of Psychoeducational Assessment, International Journal of Science and Mathematics Education, European Journal of Psychology of Education, Educational Psychology, Psychological Reports, School Science and Mathematics, Sex Roles, and International Journal of Mathematical Education in Science and Technology. Most of the top journals in mathematics anxiety literature are psychology journals regarding their scopes and only three of them directly focus on science and math education.

Bibliographic coupling of the countries showed the prevalence of the USA in the literature of maths anxiety. The other countries in this area were; England, Germany, Spain, Canada, Turkey, Italy, Australia, Israel, Austria, Netherlands, People's Republic of China, and Singapore. According to the publication years of the studies, England, Italy, Netherlands, Spain, and Israel have had the most recent publications on mathematics anxiety.

Bibliographic coupling of the authors revealed that the most influential author in mathematics anxiety literature is S.L. Beilock (from the University of Chicago, the USA). The other important authors in this area have been; E.A. Maloney, G. Ramirez, S.C. Levine, M.I. Nunez-Pena, M. Suarez-Pellicioni, D. Szucs, A. Devine, I.C. Mammarella, E.A. Gunderson, H.C. Nuerk, M. Baloglu. Among these most critical authors, top four of them are from University of Chicago, the next two ones are from the University of Barcelona and the next couple of the authors are from University of Cambridge. The most recent articles on maths anxiety have been written by a research team from Italy and England and authored by I.C. Mammarella, A. Devine, and D. Szucs.

According to the bibliographic coupling of the publications, Ashcraft and Kirk (2001) was the most influential publication. The second and the fourth most robust articles have also been first authored by the same scholar (Ashcraft, 2002; Ashcraft \& Krause, 2007). Although Ashcraft has authored some of the most influential articles, he has not been included in the list of the most influential authors due to his less number of publications in this area after the year 2000. Here are the most influential publications within their clusters in which they have maximum citation links with one another: The first cluster includes; Ferla et al. (2009), Frenzel et al. (2007), Goetz et al. (2007), Lee (2009), and Martin and Marsh (2008). The second cluster includes; Ashcraft and Kirk (2001), Ashcraft (2002), Ashcraft \& Krause (2007), and Imbo \& Vandierendonck (2007). The third cluster includes; Beilock et al. (2010), Gunderson et al. (2012), and Ma \& Xu (2004). Except for a few articles, the publications co-authored by the same research teams have been classified in the same clusters. This classification might have been due to the co-citation links between these articles.

Bibliographic coupling of the institutions showed that the most influential institution in the mathematics anxiety literature is University of Chicago (USA) with a significant difference. The results of the bibliographic coupling of the authors, which reveals that the most important four authors in this area have been affiliated with the University of Chicago, also corroborate this finding. The other outstanding institutions in this area have been; University of Cambridge (England), University of Barcelona (Spain), University of Padua (Italy), University of Oxford (England), University of Haifa (Israel), University of California, Los Angeles (USA), University of Tubingen 
(Germany), Stanford University (USA), Queen's University Belfast (Northern Ireland), University of Western Ontario (Canada), University of Munich (Germany), University of Konstanz (Germany), and Gaziosmanpasa University (Turkey). Among the most influential institutions in this area, there are three from the USA, three from Germany, and two from England. Also, the universities that hosted the most recently published articles have been; University of Cambridge, University of Padua, University of California, Los Angeles, and Queen's University Belfast.

Math anxiety has so far attracted the interests of many scholars from all around the world; however this subject has been a matter of interest in the USA more than everywhere in the world. Having had the biggest numbers of publications, citations, and the total link strength among all the countries, the USA has been the top country in this area. Besides, the most important four authors in this area are from the USA, and the strongest institutions are from the USA regarding both quality and quantity. Mathematics anxiety of the students is being regarded as a serious educational problem in the USA and studies are reveling that $25 \%$ of 4 -year college students and $80 \%$ of community college students have moderate to high levels of maths anxiety (Chang \& Beilock, 2016). Ashcraft (2002) also explained how "U.S. culture abounds with attitudes that foster math anxiety". The highest interests of the US scholars in math anxiety issue may have stemmed from their attempts to find solutions for this nation-wide problem.

Maths anxiety has also been viewed as a serious issue in all over the world, as it was proven in the 2012 Programme for International Student Assessment (PISA) that 33\% of 15-year-old students, which is the average of the 65 countries participated in this programme, had feelings of helplessness when dealing with mathematical problems (Organization for Economic Co-operation and Development [OECD], 2013). There is a boost of scientific studies in this area of research all over the world, as a response to the rising problems of modern society in maths education. Among a bulk of the research, this study has only sorted out the most prestigious databases to extract substantial scientific information. Providing insight into the trend of scientific studies in this area, the results of this study contribute to the mathematics anxiety literature.

\section{REFERENCES}

Ashcraft, M. H. (2002). Math anxiety: Personal, educational, and cognitive consequences. Current directions in psychological science, 11(5), 181-185. https:/ / doi.org/10.1111/1467-8721.00196

Ashcraft, M. H., \& Kirk, E. P. (2001). The relationships among working memory, math anxiety, and performance. Journal of experimental psychology: General, 130(2), 224. https:/ / doi.org/10.1037/0096-3445.130.2.224

Ashcraft, M. H., \& Krause, J. A. (2007). Working memory, math performance, and math anxiety. Psychonomic Bulletin \& Review, 14(2), 243-248.

Beilock, S. L., Gunderson, E. A., Ramirez, G., \& Levine, S. C. (2010). Female teachers' math anxiety affects girls' math achievement. Proceedings of the National Academy of Sciences, 107(5), 1860-1863. https:/ / doi.org/10.1073/pnas.0910967107

Chang, H., \& Beilock, S. L. (2016). The math anxiety-math performance link and its relation to individual and environmental factors: A review of current behavioral and psychophysiological research. Current Opinion in Behavioral Sciences, 10, 33-38. https:/ / doi.org/10.1016/j.cobeha.2016.04.011

Eck, N. J., \& Waltman, L. (2010). Software survey: VOSviewer, a computer program for bibliometric mapping. Scientometrics, 84(2), 523-538. https:/ / doi.org/10.1007/s11192-009-0146-3

Eck, N.J., \& Waltman, L. (2014a). CitNetExplorer: A new software tool for analyzing and visualizing citation networks. Journal of Informetrics, 8(4), 802-823.

Eck, N.J., \& Waltman, L. (2014b). Systematic retrieval of scientific literature based on citation relations: Introducing the CitNetExplorer tool. In Proceedings of the First Workshop on Bibliometric-enhanced Information Retrieval (BIR 2014), 13-20.

Eck, N. J., Waltman, L., \& Glänzel, W. (2017). Citation-based clustering of publications using CitNetExplorer and VOSviewer. Scientometrics, 111(2), 1053-1070. https:/ / doi.org/10.1007/s11192-017-2300-7

Ferla, J., Valcke, M., \& Cai, Y. (2009). Academic self-efficacy and academic self-concept: Reconsidering structural relationships. Learning and Individual Differences, 19(4), 499-505. https:/ / doi.org/10.1016/j.lindif.2009.05.004

Frenzel, A. C., Pekrun, R., \& Goetz, T. (2007). Girls and mathematics-A “hopeless" issue? A control-value approach to gender differences in emotions towards mathematics. European Journal of Psychology of Education, 22(4), 497. https:/ / doi.org/10.1007/BF03173468

Garfield, E. (2009). From the science of science to Scientometrics visualizing the history of science with HistCite software. Journal of Informetrics, 3(3), 173-179. https:/ / doi.org/10.1016/j.joi.2009.03.009 
Goetz, T., Frenzel, A. C., Pekrun, R., Hall, N. C., \& Lüdtke, O. (2007). Between-and within-domain relations of students' academic emotions. Journal of Educational Psychology, 99(4), 715. https://doi.org/10.1037/00220663.99.4.715

Gunderson, E. A., Park, D., Maloney, E. A., Beilock, S. L., \& Levine, S. C. (2018). Reciprocal relations among motivational frameworks, math anxiety, and math achievement in early elementary school. Journal of Cognition and Development, 19(1), 21-46. https:/ / doi.org/10.1080/15248372.2017.1421538

Gunderson, E. A., Ramirez, G., Levine, S. C., \& Beilock, S. L. (2012). The role of parents and teachers in the development of gender-related math attitudes. Sex Roles, 66(3-4), 153-166. https:/ / doi.org/10.1007/s11199011-9996-2

Imbo, I., \& Vandierendonck, A. (2007). The development of strategy use in elementary school children: Working memory and individual differences. Journal of Experimental Child Psychology, 96(4), 284-309. https://doi.org/10.1016/j.jecp.2006.09.001

Lee, J. (2009). Universals and specifics of math self-concept, math self-efficacy, and math anxiety across 41 PISA 2003 participating countries. Learning and Individual Differences, 19(3), 355-365. https:/ / doi.org/10.1016/j.lindif.2008.10.009

Ma, X. (1999). A meta-analysis of the relationship between anxiety toward mathematics and achievement in mathematics. Journal for Research in Mathematics Education, 30, 520-540. https:/ / doi.org/10.2307/749772

Ma, X., \& Xu, J. (2004). The causal ordering of mathematics anxiety and mathematics achievement: a longitudinal panel analysis. Journal of Adolescence, 27(2), 165-179. https:/ / doi.org/10.1016/j.adolescence.2003.11.003

Maloney, E. A., Ramirez, G., Gunderson, E. A., Levine, S. C., \& Beilock, S. L. (2015). Intergenerational effects of parents' math anxiety on children's math achievement and anxiety. Psychological Science, 26, 1480-1488. https:/ / doi.org/10.1177/0956797615592630

Markovits, Z. (2011). Beliefs hold by pre-school prospective teachers toward mathematics and its teaching. Procedia - Social and Behavioral Sciences, 11, 117-121.

Martin, A. J., \& Marsh, H. W. (2008). Academic buoyancy: Towards an understanding of students' everyday academic resilience. Journal of School Psychology, 46(1), 53-83. https:/ / doi.org/10.1016/j.jsp.2007.01.002

McBurney, M. K., \& Novak, P. L. (2002). What is bibliometrics and why should you care?. In Professional Communication Conference, 2002. IPCC 2002. Proceedings. IEEE International (pp. 108-114). IEEE.

Pritchard, A. (1969). Statistical bibliography or bibliometrics. Journal of documentation, 25(4), 348-349.

Organization for Economic Co-operation and Development (2013). PISA 2012 results: Ready to learn: Students' engagement, drive and self-beliefs (Vol. 3). Paris, France. https:/ / doi.org/10.1787/9789264201170-en

Pletzer, B., Kronbichler, M., Nuerk, H.-C., \& Kerschbaum, H. H. (2015). Mathematics anxiety reduces default mode network deactivation in response to numerical tasks. Frontiers in Human Neuroscience, 9, 202. https://doi.org/10.3389/fnhum.2015.00202

Ramirez, G., Hooper, S. Y., Kersting, N. B., Ferguson, R., \& Yeager, D. (2018). Teacher math anxiety relates to adolescent students' math achievement. AERA Open, 4(1), 1-13.

Ramirez, G., Shaw, S. T., \& Maloney, E. A. (2018). Math anxiety: Past research, promising interventions, and a new interpretation framework. Educational Psychologist, 145-164. https:/ / doi.org/10.1080/00461520.2018.1447384

Sarkar, A., Dowker, A., \& Kadosh, R. C. (2014). Cognitive enhancement or cognitive cost: trait-speplomin' cific outcomes of brain stimulation in the case of mathematics anxiety. Journal of Neuroscience, 34(50), 16605-16610. https:/ / doi.org/10.1523/JNEUROSCI.3129-14.2014

Vukovic, R. K., Roberts, S. O., \& Green Wright, L. (2013). From parental involvement to children's mathematical performance: The role of mathematics anxiety. Early Education $\mathcal{E}$ Development, 24(4), 446-467. https:/ / doi.org/10.1080/10409289.2012.693430

Wang, Z., Lukowski, S. L., Hart, S. A., Lyons, I. M., Thompson, L. A., Kovas, Y., Mazzocco, M. M., \& Petrill, S. A. (2015). Is math anxiety always bad for math learning? The role of math motivation. Psychological Science, 26, 1863-1876. https:/ / doi.org/10.1177/0956797615602471

\section{http://www.ejmste.com}

